\title{
Multiscale, Multimodal Imaging of Structure and Function Reveals Mechanisms of Normal and Abnormal Cardiac Physiology
}

\author{
Yusuf Olgar ${ }^{1}$, Alec Miler ${ }^{1}$, Heather Struckman ${ }^{2}$, Rengasayee Veeraraghavan ${ }^{1}$ and Przemyslaw \\ Radwanski ${ }^{1}$
}

${ }^{1}$ The Ohio State University, Columbus, Ohio, United States, ${ }^{2}$ The Ohio State University, Hilliard, Ohio, United States

While it has long been known that proteins that exist in close proximity influence each other's function, it is increasingly appreciated that there exist specialized structural nanoscale that act as functional units of cardiac biophysical phenomena. Notably, recent evidence from our group[1-3] and others [4, 5] suggests that a subset of $\mathrm{Na}_{\mathrm{v}}$ channels reside in a close proximity to $\mathrm{Ca}^{2+}$ handling machinery $\left(\mathrm{Ca}^{2+}\right.$ release channels, ryanodine receptors; RyR2, and $\mathrm{Na}^{+} / \mathrm{Ca}^{2+}$ exchange; NCX). This suggest that these $\mathrm{Na}_{\mathrm{v}}$ channels may contribute to the modulation of $\mathrm{Ca}^{2+}$ release. For instance, loss-of-function mutations in $\mathrm{Na}_{\mathrm{v}} 1.1$ (Dravet Syndrome) have previously been shown to cause an increase in the incidence of epileptic seizures and cardiac arrhythmias[6,7]. Interestingly, this loss-of-function mutation leads to an increase in $\mathrm{Na}^{+}$influx into the cardiomyocyte, thereby precipitating arrhythmias through $\mathrm{Ca}^{2+}$ handling dysregulation. Surprisingly, reduction in $\mathrm{Na}_{v} 1.6$ decreased the incidence of epileptic seizures, suggesting a possible link between $\mathrm{Na}_{v} 1.6$ and cardiac arrhythmias in Dravet Syndrome[8,9]. Hence, we hypothesize that changes in $\mathrm{Na}_{\mathrm{v}} 1.6$ functional expression in close proximity to $\mathrm{Ca}^{2+}$ handling machinery contributes to arrhythmias in $\mathrm{Na}_{\mathrm{v}} 1.1$ haploinsufficiency.

Proximity ligation assay, which allows assessment of pairs of proteins that are within $40 \mathrm{~nm}$, reveals that Dravet cardiomyocytes evidence an increase in the number of $\mathrm{Na}_{\mathrm{v}} 1.6-\mathrm{RyR} 2$ and $\mathrm{Na}$ 1.6-NCX proximity points along the transverse-tubules relative to wild type cardiomyocytes. Additionally, Stochastic Optical Reconstruction Microscopy (STORM) in Dravet hearts reveals an increases in Nav1.6 clusters within 50 $\mathrm{nm}$ of RyR2, but not further away, suggesting that remodeling within these nanodomains may contribute to increased $\mathrm{Na}^{+}$influx and the resulting abnormal $\mathrm{Ca}^{2+}$ handling in these mice.

To gain insight into the functional consequences of nanodomain remodeling in Dravet, we first performed scanning ion conductance microscopy (SICM)-guided patch clamp. This approach allows positioning of patch clamp pipet with $20-40 \mathrm{~nm}$ precision on cardiomyocytes surface. SICM-guided patch clamp revealed an increase in local $\mathrm{Na}_{\mathrm{v}}$ activity within the cardiomyocyte transverse-tubules and not in other regions. This increase in local $\mathrm{Na}_{\mathrm{v}}$ activity was coupled to increased aberrant $\mathrm{Ca}^{2+}$ release in the form of $\mathrm{Ca}^{2+}$ sparks. Additionally, Dravet cardiomyocytes evidenced increased $\mathrm{Ca}^{2+}$ wave incidence. These abnormalities in $\mathrm{Ca}^{2+}$ handling translated into increased ventricular tachycardia incidence in vivo. Consistent with increased Nav1.6 in Dravet mice, reduction in $\mathrm{Na}_{v} 1.6$, either pharmacologic or through genetic means, resulted in a reduction in aberrant $\mathrm{Ca}^{2+}$ release on cellular level and arrhythmia burden in vivo. 
In summary, multiscale, multimodal imaging of structure and function uncovers $\mathrm{Na}_{\mathrm{v}} 1.6$ remodeling within transverse-tubules in a Nav1.1 haploinsufficiency. Importantly, these structural changes correlated with increased $\mathrm{Na}_{\mathrm{v}}$ activity, $\mathrm{Na}_{v}$-mediated $\mathrm{Ca}^{2+}$ handling dysfunction and increased ventricular tachycardia incidence. These results suggest that remodeling within $\mathrm{Na}^{+} / \mathrm{Ca}^{2+}$ handling nanonodomains may contribute to the development of ventricular tachycardia.

References

[1] PB Radwański et al. Cardiovasc Res 106 (2015), p. 143.

[2] PB Radwański et al. JACC Basic Transl Sci 1 (2016), p. 251.

[3] HL Struckman et al. Microsc Microanal (2020), p. 1.

[4] SKG Maier et al. Circulation 109 (2004), p1421.

[5] RE Westenbroek et al. J Mol Cell Cardiol 64 (2013), p. 69.

[6] DS Auerbach et al. PloS One 8 (2013), e77843.

[7] F Kalume et al. J Clin Invest 123 (2013), p. 1798.

[8] MS Martin MS et al. Hum Mol Genet 16 (2007), p . 2892.

[9] LL Anderson et al. Sci Rep 7 (2017), p. 1682. 